\title{
Catechol neurochemistry in the autonomic clinic: helpful but not absolutely required
}

\author{
Jeremy K. Cutsforth-Gregory ${ }^{1}$ \\ Received: 9 May 2018 / Accepted: 10 May 2018 / Published online: 23 May 2018 \\ (c) Springer-Verlag GmbH Germany, part of Springer Nature 2018
}

Keywords Catecholamines · Autonomic testing $\cdot$ Dysautonomia $\cdot$ Norepinephrine $\cdot$ Epinephrine $\cdot$ Dopamine

This issue of Clinical Autonomic Research brings the next installment in the series on Autonomic Function Testing. Goldstein and Cheshire provide a tour-de-force of catechol neurochemistry that extends from the biosynthesis and metabolism of these compounds through their diagnostic and therapeutic relevance in clinical disease [2]. As usual, the authors do so thoroughly and with a writing style that will be accessible to students as much as to experts in autonomic function.

The article opens with an historical perspective on the early descriptions of catechols, important groundwork for our field laid by Irwin Kopin and Julius Axelrod. Candid photographs of these men may seem out of place in a scientific review article, but here the memorialization seems appropriate and comes first-hand from Kopin's mentee. While most readers will already be familiar with the endogenous human catecholamines (epinephrine, norepinephrine [NE], and dopamine), they will likely benefit from the concise discussions of the other catechols and their chief metabolites, even more so as they are reviewed in the context of clinical syndromes and diseases that alter their levels and ratios.

Particularly important, and reflected in the structure of this review, is the fact that plasma catechol testing is rarely diagnostic in isolation but is frequently supportive in light of other clinical, radiographic, or laboratory features. As these authors have previously argued [1,3], nothing replaces the well-performed medical history-taking and physical

This comment refers to an article available at https://link.springer. com/article/10.1007/s10286-018-0528-9.

Jeremy K. Cutsforth-Gregory

CutsforthGregory.Jeremy@ mayo.edu

1 Department of Neurology, Mayo Clinic, Rochester, MN, USA examination in the assessment of suspected autonomic dysfunction. For those clinicians or researchers who choose to pursue catechol testing in their patients or subjects, the authors provide a detailed protocol, in Table 2, for collecting and processing samples.

Perhaps most helpful for the clinician is the extended discussion of many of the common and uncommon autonomic disorders and their respective neurochemical patterns (summarized in Table 1). For example, the clinician is often faced with a patient with parkinsonism and some degree of orthostatic lightheadedness. Is this run-of-the-mill Parkinson disease (PD), dementia with Lewy bodies (DLB), or multiple system atrophy (MSA)? This question can sometimes be answered with the help of neuroimaging [6], cardiac metaiodobenzylguanidine scintigraphy [8], or autonomic reflex screen and thermoregulatory sweat test [5] data, but these diagnostic tools are not always available or the results revealing. Enter plasma catechol testing. $\mathrm{OH}$ will be associated with a low 3,4-dihydroxyphenylglycol (DHPG) to $\mathrm{NE}$ ratio in $\mathrm{PD}$, low $\mathrm{NE}$ and blunted orthostatic change in DLB, and normal NE when supine and standing and normal DHPG in MSA. The authors classify the catechol pattern in MSA as unhelpful, but in fact normal NE and DHPG in the setting of parkinsonism and $\mathrm{OH}$ is quite telling. Similarly, normal NE (and DHPG) predicts conversion to a central synucleinopathy in patients whose initial phenotype suggests pure autonomic failure $[4,7]$.

Goldstein and Cheshire have brought together a great deal of work on clinical catechol neurochemistry in a concise review. While catechol testing is not necessary in every patient, it can be informative in many and diagnostic in a few. Such testing should be considered as we seek additional clarity in the often murky world of "dysautonomia". 


\section{Compliance with ethical standards}

Conflict of interest None.

Funding sources None.

\section{References}

1. Cheshire WP Jr, Goldstein DS (2018) The physical examination as a window into autonomic disorders. Clin Auton Res 28:23-33

2. Goldstein DS, Cheshire WP (2018) Roles of catechol neurochemistry in autonomic function testing. Clin Auton Res. https://doi. org/10.1007/s10286-018-0528-9

3. Goldstein DS, Cheshire WP Jr (2017) The autonomic medical history. Clin Auton Res 27:223-233

4. Kaufmann H, Norcliffe-Kaufmann L, Palma JA, Biaggioni I, Low PA, Singer W, Goldstein DS, Peltier AC, Shibao CA, Gibbons $\mathrm{CH}$, Freeman R, Robertson D, Autonomic Disorders Consortium
(2017) Natural history of pure autonomic failure: a United States prospective cohort. Ann Neurol 81:287-297

5. Kimpinski K, Iodice V, Burton DD, Camilleri M, Mullan BP, Lipp A, Sandroni P, Gehrking TL, Sletten DM, Ahlskog JE, Fealey RD, Singer W, Low PA (2012) The role of autonomic testing in the differentiation of Parkinson's disease from multiple system atrophy. J Neurol Sci 317:92-96

6. Peran P, Barbagallo G, Nemmi F, Sierra M, Galitzky M, Traon AP, Payoux P, Meissner WG, Rascol O (2018) MRI supervised and unsupervised classification of Parkinson's disease and multiple system atrophy. Mov Disord 33:600-608

7. Singer W, Berini SE, Sandroni P, Fealey RD, Coon EA, Suarez MD, Benarroch EE, Low PA (2017) Pure autonomic failure: predictors of conversion to clinical CNS involvement. Neurology 88:1129-1136

8. Yang T, Wang L, Li Y, Cheng M, Jiao J, Wang Q, Guo H (2017) (131)I-MIBG myocardial scintigraphy for differentiation of Parkinson's disease from multiple system atrophy or essential tremor in Chinese population. J Neurol Sci 373:48-51 